\title{
A CORRELAÇÃO DO EXCESSO DE ÁCIDO FÓLICO NA GESTAÇÃO E O TRANSTORNO DO ESPECTRO AUTISTA (TEA)
}

\section{ARTIGO DE REVISÃO}

SILVA, João Batista De Menezes ${ }^{1}$

SILVA, João Batista De Menezes. A correlação do excesso de ácido fólico na gestação e o transtorno do Espectro Autista (TEA). Revista Científica Multidisciplinar Núcleo do Conhecimento. Ano 05, Ed. 12, Vol. 09, pp. 152-166. Dezembro de 2020. ISSN: 2448-0959, Link de acesso: https://www.nucleodoconhecimento.com.br/saude/acido-folico

\section{RESUMO}

Objetivo: Elucidar se a hipersuplementação com ácido fólico antes, durante e pós gestação pode estar realmente atrelado ao desencadeamento do transtorno do espectro autista (TEA). Metodologia: A pesquisa trata-se de uma revisão bibliográfica integrativa de abordagem qualitativa, realizada na base de sites eletrônicos, monografia, revista de saúde (Rebis), dados da biblioteca eletrônica SciELO (Scientific Electronic Library Online), Literatura Latino-Americano e do Caribe em Ciências da Saúde (LILACS), Base de Dados de Enfermagem (BDENF), BVS (Biblioteca virtual em saúde), utilizando os seguintes descritores: autismo, causas do autismo, excesso de ácido fólico na gravidez, associado ao autismo. Resultados: Os critérios de inclusão das publicações foram: artigos de revistas originais, publicadas no período de abril de 2004 a dezembro de 2019, tomando por base compreender artigos com informações atuais sobre o tema que estivesse disponíveis na integra gratuitamente na internet ou no acervo da biblioteca da instituição onde este estudo foi realizado. Para o objetivo da pesquisa foram encontrados 107 artigos. Conclusão: Ao se analisar o riscobenefício da hipersuplementação de ácido fólico nas dosesagem acima do

1 Pós Graduado Em Saúde Pública E Urgência E Emergência, Graduado Em Enfermagem. 
recomendado, conclui-se que os benefícios subrepujam as possibilidades de risco de desenvolver (TEA).

Palavras-Chaves: Transtorno do Espectro Do Autismo (TEA), causas do autismo, ácido fólico, autismo.

\section{INTRODUÇÃO}

Autismo, do grego autós, significa "de si mesmo". Esse termo foi empregado pela primeira vez pelo psiquiatra suíço Eugene Bleuler em 1911. Bleuler tentou descrevêlo como a "fuga da realidade e o retraimento interior dos pacientes acometidos de esquizofrenia" (CUNHA, 2012, p. 20). Hoje, o autismo não é mais considerado um tipo de psicose nem esquizofrenia. Na década de 1980, passou a ser nomeado transtorno invasivo do desenvolvimento (TID) (BRASIL, 2015).

O Transtorno do Espectro do Autismo (TEA) é um grupo de disfunções no desenvolvimento neurológico, sendo mais prevalente no sexo masculino afetando cerca de $1 \%$ da população. É definido por comprometimentos da capacidade social e da comunicação verbal e não verbal, e comportamentos de movimentos repetitivos. Embora seja definido por esses principais indícios, pacientes autistas tem características como falta de concentração, abrangendo deficiência intelectual e também pessoas com quociente de inteligência normal, podendo ter assim vida regular, além disso pode também apresentar disfunções no sono, hiperatividade e até mesmo epilepsia. (OLIVEIRA; SERTIE, 2017)

De acordo com o CDC (Center of deseases control na prevention), 1 em cada 110 crianças desenvolveram autismo, possuindo assim mais de 1,9 milhões de crianças autistas em todo o Brasil, embora os inúmeros casos existentes, pessoas com autismo ainda sofrem para conseguirem um tratamento adequado por ainda haver dúvidas relacionadas as possíveis Causas. (RAMÔA et al., 2018)

A vitamina B9, é conhecida como folato ou ácido fólico, ela pode ser adquirida por meio de alimentos como folhas verdes, fígados, frutas... O ácido fólico é importante 
no desenvolvimento do tubo neural, porem esse fechamento pode ocorrer no mesmo tempo do desenvolvimento do transtorno do Espectro do Autismo (TEA), por isso algumas pesquisas apontam o ácido fólico como um dos prováveis fatores responsáveis pelo desenvolvimento do autismo. (MAIA et al., 2019)

Algumas dessas razões é a genética associada a nutrição. E confirmado pela ciência que determinado DNA responsável pela maturação cerebral, denominado neurodesenvolvimento do embrião, quando diante do exagero de ácido fólico estabelece uma expressão desacertada, levando a criança a ter contrariedades nas questões cognitivas e emotivas, associadas ao autismo. (CABRAL, 2017).

\section{MÉTODO}

A pesquisa trata-se de uma revisão bibliográfica integrativa e abordagem qualitativa, realizada na base de sites eletrônicos,), dados da biblioteca eletrônica SciELO (Scientific Electronic Library Online), Literatura Latino-Americano e do Caribe em Ciências da Saúde (LILACS), BVS (Biblioteca virtual em saúde), utilizando os seguintes descritores: autismo, causas do autismo, excesso de ácido fólico na gravidez, associado ao autismo.

Os critérios de inclusão das publicações foram: artigos e revistas originais, publicadas no período de abril de 2004, a dezembro de 2019, tomando por base compreender artigos com informações atuais sobre o tema que estivesse disponível na integra gratuitamente na internet ou no acervo da biblioteca da instituição onde este estudo foi realizado. Para o objetivo da pesquisa foram encontrados 79 artigos.

Após a utilização dos critérios de inclusão, foram selecionados apenas 32 artigos para a composição do estudo. Como tema central: Excesso de suplementação do ácido fólico na gravidez, está associada a causa do transtorno do espectro autista (TEA)? Sobre o tema principal, teve uma escassez de resultados, e vale ressaltar que os artigos para o objetivo da pesquisa obtiveram-se carência em publicações nas diversas fontes pesquisadas. Depois dessa seleção fizemos a leitura por completo dos artigos escolhidos. E posteriormente realizamos a análise crítica desses artigos. Para 
análise dos dados foram criadas categorias temáticas de acordo com o agrupamento dos conteúdos encontrados, tomando por base a nossa questão norteadora.

\section{RESULTADOS}

\section{AUTISMO}

O termo autismo foi apresentado pela primeira vez por Leo Kanner em 1943 publicando o artigo "Os distúrbios autísticos de contato afetivo", utilizado para retratar sintomas de esquizofrenia que se caracteriza por isolamento e apatia por objetivos e pessoas. O autismo acompanha os princípios da psiquiatria desde o século XVIII ao século XIX, No início pessoas com TEA eram diagnosticados de "idiotas". Ainda hoje existem dúvidas se o quadro diagnóstico pode ser uma psicopatologia ou deficiência, apesar de que os campos das neurociências e teorias comportamentais, dizem que o transtorno do espectro autista está ligada a deficiência. (SILVA; FURTADO, 2019). O transtorno do espectro do autismo (TEA), corresponde a uma desordem do neurodesenvolvimento que abrange o autismo, como características da síndrome de Rett, síndrome de asperger, inquietação desintegrativa infantil e desorientação global do desenvolvimento, (MANUELA et al., 2020). Sendo assim, o quadro clínico compreende padrões restritos e repetitivos de comportamento, interesse ou atuação, cujo os primeiros indícios aparecem na primeira infância. (FERNANDA et al., 2019).

O (TEA) afeta o autista de maneira precoce e crônica, antes mesmo dos seus 3 anos de idade, agindo com dificuldade de interação social, medo ansiedade ou indiferença, podendo assim identificar alguns sinais em evidência nos seus primeiros anos de vida, seus progressos nas áreas sociais e comunicativas, traz prejuízos futuros aos indivíduos portadores do transtorno. Porém devemos entender que as dificuldades impostas pelo (TEA) não são necessariamente limitadas, nada que os impeça de interagir e se expressar. (LEMOS et al., 2020).

Uma em cada cinquenta e oito crianças são diagnosticadas com o (TEA), acredita- se que existam cerca de 2 milhões de pessoas com autismo no Brasil, levando em consideração um subgrupo familiar, que é primordial em qualquer diagnóstico do 
autismo, levando em conta uma maior taxa de recorrência, são eles: irmãos gêmeos de pais iguais, um alto número de parentes diagnosticados com o transtorno, e em grande índice que seja denominado do sexo masculino. (ZANOLLA et al., 2020).

Seus sinais mais notáveis são caracterizados por: fascinação a luzes ou objetos que giram e se movimentam, gesticulação mal interpretada ao ouvir sons ou sentir texturas específicas, cheiro excessivo e não saber distinguir dor ,calor ou frio. (POSAR; VISCONTI, 2018).

\section{IMPACTO DO DIAGNÓSTICO PARA OS FAMILIARES}

Após o diagnóstico do autismo, muitas mudanças ocorrem e com essas mudanças, o sentimento de tristeza e negação por parte da família é comum. Em muitas situações, os pais precisam abdicar de seus empregos para dar o cuidado necessário para a criança com autismo, e isso causa um comprometimento financeiro. Outra grande situação difícil para os pais está em frequentar ambientes, tanto para o filho, pois o mesmo não se adapta a qualquer lugar, como para as pessoas que muitas vezes não compreendem o que se passa com a criança. O medo de como será o futuro da criança é algo que surge com frequência na cabeça dos familiares. (HOFZMANN et al., 2019).

Em muitos casos a negação por parte da família no diagnóstico do autismo se dar devido à falta de conhecimento sobre a doença, pois eles se sentem pouco informados em relação à doença e ficam sem compreender do que ela se trata, dessa forma, o vínculo entre a família e o profissional de saúde tem uma grande relevância, pois o atendimento prestado de forma que faça a família se sentir acolhida, faz com que os mesmos fiquem esclarecidos e encarem a situação de uma forma mais positiva. (PINTO et al., 2016).

\section{DIAGNÓSTICO E TRATAMENTO}

Embora o transtorno do espectro autista tenha características específicas na primeira infância. Estudos de Goin-Kochel, Mackintosh, \& Myers demostraram que os meninos 
tendem a ser diagnosticados antes que as meninas, parte dos estudos não encontrou associação entre a raça da criança e a IRD do autismo, todavia algumas pesquisas demostraram que as crianças afro-americanas negras são diagnosticadas após a idade que crianças brancas. (ZANON et al., 2017).

No Brasil ainda não foi executado nenhum estudo averiguador relacionado a idade da realização de diagnóstico do autismo por falta de ausência de profissionais da área da saúde qualificados para a identificação precoce do autismo como também dificuldade aos serviços, baixo nível sociocultural, fazendo com que crianças com autismo no Brasil pode ser ainda mais difícil dos que residem em países norteamericanos ou europeus. (ZANON et al., 2017)

O diagnóstico do autismo traz danos sociais para indivíduos que tem o transtorno como também para seus familiares. A história, a família, o contexto e as vivencias apresentadas pela pessoa com autismo são fundamentais para um diagnóstico eficaz. É de suma importância que o processo de diagnostico seja executado por uma equipe multiprofissional e multidisciplinar com experiência clínica que vão analisar exames neurológicos, metabólicos e genéticos, realizando atendimentos individuais, atendimento familiar, atividades livres, para assim finalizar o processo de diagnóstico do autismo. (BRASIL, 2015).

É imprescindível um olhar qualificado para a pessoa com autismo, e também da família, podendo analisar: história da vida, laços familiares, rotina, história clínica, queixas da pessoa com autismo e da família entre outros e também os marcos de desenvolvimentos. O método de diagnóstico é o momento inicial do levantamento de um projeto terapêutico que será formado diante das informações da família. Embora o diagnóstico definitivo do autismo só seja definido após os três anos de vida a identificação de risco para o autismo pode e deve ser feita precocemente e é um dever do Estado. (BRASIL, 2015). 


\section{TRATAMENTO}

As intervenções para os transtornos globais do desenvolvimento, devem ser de forma multidisciplinares, considerando os pontos da fonoaudiologia, nutrição, psicologia e entre outros. (CARVALHO et al., 2012).

A finalidade do tratamento com pessoas com o transtorno do espectro autista, é diminuir as angústias e dificuldades do indivíduo, aumentando a aprendizagem e buscando melhorias. Amparar a família e inserir ela como uma ajuda nesse tratamento, sem cobrar dela o papel do terapeuta, é muito relevante, pois ajuda muito nesse processo de cuidado. Além do acompanhamento dos demais profissionais, que é bastante fundamental. Ainda não foram criados medicamentos próprios para o autismo, visto que, os psicofármacos existentes não tratam exclusivamente esse transtorno, pois não melhoram na comunicação, nos interesses e nas dificuldades sociais. Porém, existem medicamentos que melhoram a convivência do autista com seus familiares, desenvolvendo uma evolução positiva quanto as agressividades, descontroles, insônia e inquietação. Comportamentos repetitivos e estereotipias motoras também podem ser diminuídas com o uso de medicamentos psiquiátricos. Os medicamentos não podem ser usados como o essencial recurso terapêutico para o autista, devem está relacionado com outros meios de cuidado. (BRASIL, 2013).

\section{CARACTERÍSTICAS CLÍNICAS DE CRIANÇAS COM RISCO PARA TEA}

Quadro 1 Características Clínicas de Crianças com Risco para TEA

\begin{tabular}{|l|l|l|}
\hline De 6 a 8 meses & De 12 a 14 meses & Por volta de 18 meses \\
\hline Não apresenta iniciativa & Não responde & Não se interessa por jogos \\
em começar, provocar e & claramente quando é & de faz de conta. \\
sustentar interações com & chamado pelo nome & \\
os adultos próximos (por & & \\
\hline
\end{tabular}




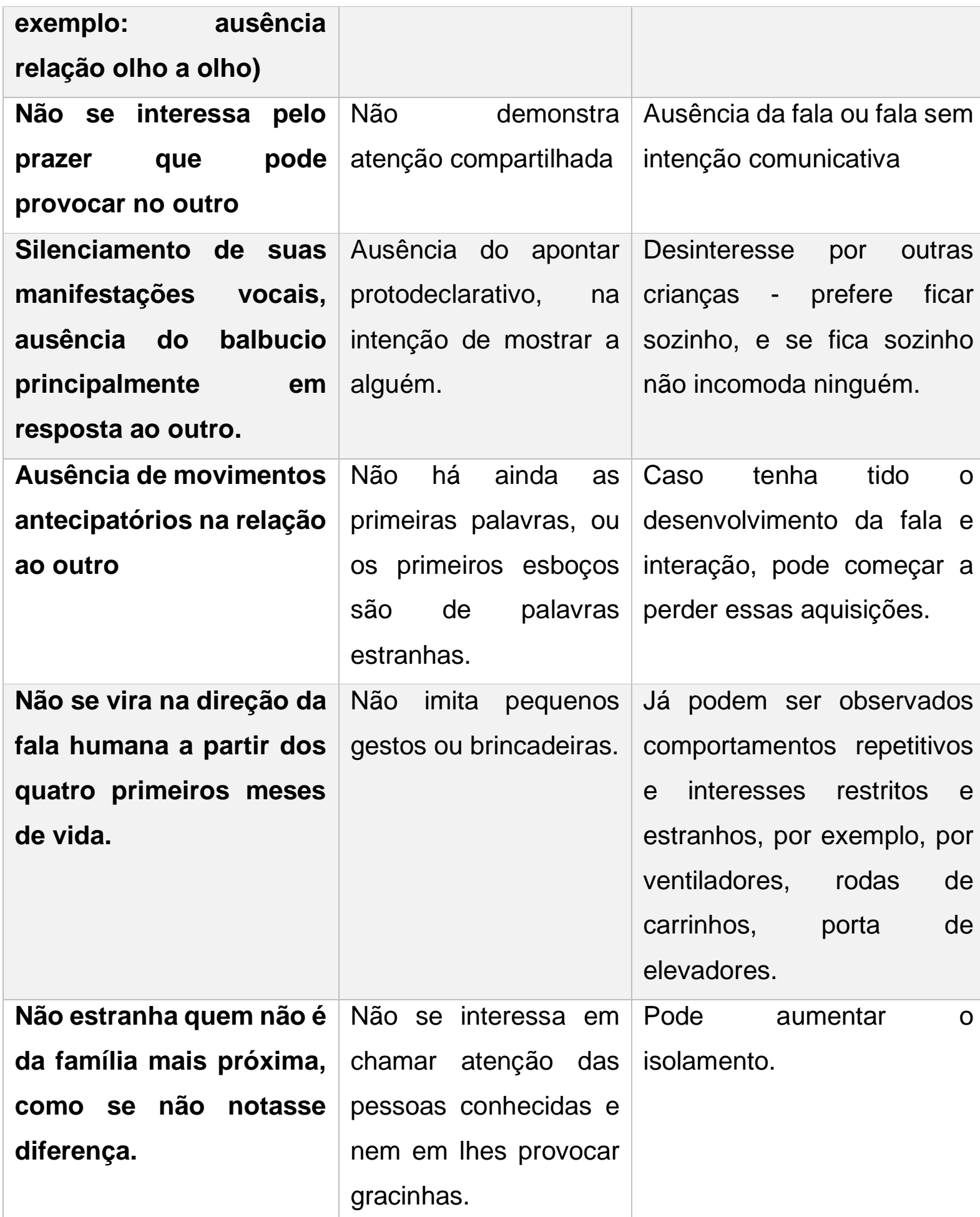

Não se vira na direção da Não imita pequenos Já podem ser observados fala humana a partir dos gestos ou brincadeiras. comportamentos repetitivos quatro primeiros meses e interesses restritos e de vida. estranhos, por exemplo, por ventiladores, rodas de carrinhos, porta de elevadores.

Não estranha quem não é Não se interessa em Pode aumentar o da família mais próxima, chamar atenção das isolamento. como se não notasse pessoas conhecidas e diferença. nem em lhes provocar gracinhas.

Fonte: Área Técnica de Saúde Mental, Álcool e Outras Drogas/Dapes/SAS/MS. 


\section{CONCEITOS DO ÁCIDO FÓLICO, SEUS BENEFícIOS E SEUS POSSÍVEIS MALEFÍCIOS}

Conhecido como folato, ou vitamina B9 o ácido fólico pode ser encontrado em cápsulas e em vegetais de coloração verde escuro, frutas cítricas, fígados, grãos e sementes, conhecido pela sua forma sintética o ácido fólico, definido como uma vitamina hidrossolúvel, também é classificado como um composto químico. O folato se originou no ano de 1935, quando ocorreu uma série de distúrbios consequentes de um déficit nutricional, vindo a ser descoberto pela hematologista Lucy wills, ganhando esse nome em 1941 no qual foi isolado das folhas de um espinafre. (MAIA et al., 2019).

Passou a ser conhecido no ano de 1991 por sua suplementação no período Peri concepcional, e no primeiro trimestre de gravidez pela diminuição de defeito do tubo neural, lábio leporino e algumas espécies de distúrbios cardíacos. (RAMÔA et al., 2018). Cerca de 53 países existe a lei de uso obrigatório para suplementação de ácido fólico na gestação, no Brasil a recomendação de ácido fólico é de $100 \mathrm{~g}$ e passou a ser obrigatório em junho de 2014. (SANTOS, 2013).

As malformações congênitas são definidas por anormalidades do desenvolvimento embrionário, identificadas no nascimento, sendo uma das principais causas de morte infantil. Portanto mulheres com idades férteis e recomendado tomar $0,4 \mathrm{mg}=400 \mathrm{ug}$ suplementares, todos os dias se estiver planejando uma nova concepção. A importância do planejamento de uma gravidez, previne os riscos de malformações uma vez que o tubo neural é fechado ao final da $5^{\circ}$ semana de gestação, onde se torna preocupante pois é exatamente nestas semanas que a paciente descobre que está gravida, onde é preconizado que seja feita a ingestão 2 meses antes de engravidar e durante os dois primeiros meses da gestação. (JARA-P et al., 2017).

Realizando o uso de forma adequada o ácido fólico pode auxiliar com a prevenção de patologias respiratórias na infância, e síndrome de Down, intercede no aumento do volume de eritrócitos, no aumento do útero e no crescimento da placenta e do feto. Sua escassez está relacionada a altos níveis de homocisteína no soro, podendo ser associado à síndrome da gravidez hipertensiva, partos prematuros, abortos 
espontâneos, doenças cerebrais, cardiovasculares e vasculares crônicas e baixo peso ao nascer. (BARCO et al., 2020).

É controverso a relação da suplementação com altas doses de ácido fólico, segundo pesquisas apontam que o ácido fólico pode ser um fator ambiental que provoca 0 transtorno, se analisados os níveis de folato na sorologia de mães de crianças autistas, e a quantidade ingerida pela sua forma sintética. $O$ fechamento do tubo neural ocorre no mesmo tempo em que pode ocorrer e desencadear 0 desenvolvimento do TEA, fato analisado durante essas duas últimas décadas, onde aconteceram várias campanhas e alertas para a suplementação pelo ácido fólico, levando em conta os níveis altos de homocisteína em sangue de crianças portadoras. (MAIA et al., 2019).

Artigos científicos abrangendo os meios de absorção do ácido fólico, falam que o fígado seja o primeiro órgão de absorvimento do ácido fólico, tendo em vista em que o fígado teria uma fraca capacidade de possibilitar a redução do ácido fólico, ocorrendo assim um aumento de ácido fólico não metabolizado na circulação sistêmica, sendo capaz de acelerar o declínio cognitivo em idosos como perca discreta de memória, falta de atenção, podendo também ocorrer casos de cânceres, complicações gestacionais, e doenças cardiovasculares. Sendo assim a suplementação de ácido fólico seja recomendada e fornecida como uma intervenção de saúde pública no Brasil durante o pré-natal a inadequação de seu uso foi comprovada. tendo vantagens para alguns grupos populacionais e prejudiciais para outros. (KIMI et al., 2010).

\section{SUPLEMENTAÇÃO EM EXCESSO DE ÁCIDO FOLICO, RELACIONADO AO AUTISMO}

O ácido fólico é absorvido pelas células a através de receptores com elevada afinidade para folato e derivados de ácido fólico reduzidos, porém é bloqueado pela presença de autoanticorpos do receptor do folato (FRAA). As FRAA cerebrais foram identificados com alta frequência em crianças com transtorno do espectro autista, levando assim a uma possível ligação entre a captação do ácido fólico e o autismo 
fazendo com que a suplementação do ácido fólico seja estudada amplamente. (ZHOU, 2018)

Os serviços de saúde pública dos Estados Unidos desde 1992 recomendam que mulheres em idades fértil consuma $400 \mu \mathrm{g}$ de ácido fólico diariamente, é interessante atentar que uma década após a efetivação é verificado que a existência do autismo aumentou radicalmente. (CASTRO, 2016), Porém não está claro se isso é um aumento real, um artefato de reportagem ou coincidência casual. (LEEMING, 2009)

De forma controversa, estudos realizados na California: 12 meses antes da gravidez e 4 semanas no período gestacional e Noruega: 4 semanas antes da fecundação até a oitava semana de gravidez, os autores afirmaram que as gestantes que fizeram o uso do ácido fólico no período gestacional favoreceu na redução para desenvolvimento do autismo. (SCANONI, 2019).

Contudo, conhecimentos adicionais são necessários para definir estratégias de investigação sobre a suplementação efeitos a longo prazo no neuro-desenvolvimento infantil. A conclusão da suplementação com ácido fólico, especialmente na gravidez, os poucos e contraditórios estudos apresentam conclusões inconsistentes pois os números reduzidos de estudos são insuficientes para uma conclusão. Há necessidade de grandes estudos que avaliem os níveis séricos e a ingestão de ácido fólico em pacientes autistas, os efeitos da suplementação de ácido fólico nos sintomas clínicos em pacientes com autismo, como a associação entre níveis celulares e suplementação durante a gravidez. (CASTRO, 2016).

\section{PAPEL DA ENFERMAGEM NA CORRETA PRESCRIÇÃO DE USO DE ÁCIDO FÓLICO E FRENTE A CRINÇAS AUTISTA}

Ao prestar assistência á saúde da mulher no período gestacional, profissionais da saúde devem identificar os fatores de riscos para a deficiência do ácido fólico. O enfermeiro deve orientar as mulheres que desejam engravidar iniciar a suplementação de ácido fólico antes da gravidez e continuar até a 14르 semana gestacional para a 
prevenção de defeitos no espaço neural e favorecer o desenvolvimento adequado do neonato. (ESPOLADOR et al., 2015).

O papel da enfermagem a hoje é o de agente terapêutico. Seu objetivo não é o diagnóstico, ou realizar prescrições, mas a qualidade de vida da criança. O cuidado deve respeitar a diferença e comportando-se com o autista como um ser humano e não como um problema a ser solucionado. A enfermagem tem oportunidades de usar diversas formas terapêuticas da sua atividade profissional, fazendo com que pessoas com autismo mantenham autonomia e cidadania, ou mesmo para reabilitá-los. (ANDRADE et al., 2005).

A assistência a uma criança com autismo é um desafio para os profissionais de saúde, a falta de qualificação em específico da enfermagem para uma assistência adequada a crianças com transtorno do espectro autista, impede que o cuidado seja realizado de uma forma apropriada, sendo necessário uma melhor qualificação para assim ter avanços no cuidado. A assistência de enfermagem deve respeitar a individualidade $e$ características de cada criança autista, com o intuito de gerar um vínculo e estar atento a evolução da criança para assim proporcionar maior segurança a todos. (BARBOSA E NUNES, 2019).

\section{CONSIDERAÇÕES FINAIS}

A pesquisa aponta para a efeito benéfico que o ácido fólico traz para a formação do feto, contribuindo para redução de até $70 \%$ do desenvolvimento do Transtorno do Espectro Autista - TEA, bem como, aponta outros fatores que são responsáveis pelo desenvolvimento do transtorno, como fatores nutricionais, genéticos e doenças do tipo Hipertensão e Diabetes. Embora alguns poucos autores tivessem divergido em seu comentário, quando se trata do uso em excesso, porém sem grandes destaques e relevância.

Entende-se que a maioria dos autores corroboram para o uso do ácido fólico ainda no planejamento familiar e que se mantenha durante o período gestacional para uma formação fetal saudável. 
A assistência à criança com autismo é um desafio para os profissionais de saúde, a falta de qualificação com destaque para o profissional enfermeiro, para uma assistência adequada a crianças com transtorno do espectro autista, contribui para o aumento do número de casos de certa forma. Sugere-se estimular profissionais de saúde a pesquisarem mais sobre o tema e implementarem medidas de prevenção para que se possam promover saúde e evitar novos casos em sua grande maioria evitáveis, se tiverem uma assistência a mulher bem conduzida.

\section{REFERÊNCIAS}

ANDRADE, R. L. P.; PEDRÃO, L. J. Algumas considerações sobre a utilização de modalidades terapêuticas não tradicionais pelo enfermeiro na assistência de enfermagem psiquiátrica. Rev Latino-am Enfermagem, v. 13, n. 5, p. 737-42, set./out., 2005. Acesso em 03 de junho de 2020.

BARCO TAVARES, Beatriz et al. Conhecimento de ácido fólico suplementar durante a gravidez. Investir. educ. enferm Medellín, v. 33, n. 3, p. 456-464, dezembro de 2015. Disponível em <http://www.scielo.org.co/scielo.php?script=sci_arttext\&pid=S0120$53072015000300009 \& \operatorname{lng}=e n \& n r m=i s o>$. Acesso em 30 de maio de 2020.

BRASIL, MINISTÉRIO DA SAÚDE. LINHA DE CUIDADO PARA A ATENÇÃO ÀS PESSOAS COM TRANSTORNOS DO ESPECTRO DO AUTISMO E SUAS FAMÍLIAS NA REDE DE ATENÇÃO PSICOSSOCIAL DO SISTEMA ÚNICO DE SAÚDE. Brasília, 2015.

Disponível

em:

https://bvsms.saude.gov.br/bvs/publicacoes/linha_cuidado_atencao_pessoas_transt ornos_autismo_versao_preliminar.pdf. Acesso em: 21 mai. 2020.

CARVALHO, J. A. D. et al. NUTRIÇÃO E AUTISMO: CONSIDERAÇÕES SOBRE A ALIMENTAÇÃO DO AUTISTA. Revista Científica do ITPAC: Araguaína, v. 5, n. 1, jan./2012. Disponível em: https://assets.unitpac.com.br/arquivos/revista/51/1.pdf. Acesso em: 22 mai. 2020. 
CASTANO, Erika et al. Folatos e gravidez, conceitos atuais: É necessária suplementação com ácido fólico? Rev. chil. pediatra Santiago, v. 88, n. 2 P. 199-206, abr. 2017.

Disponível em $<$ https://scielo.conicyt.cl/scielo.php?script=sci_arttext\&pid=S0370$41062017000200001 \& \operatorname{lng}=e s \& n r m=i s o>$. Acesso em 29 de maio de 2020.

ESPOLADOR, G. M., Jordão, B. A., Cardoso, M. G., Sabino, A. N., \& Tavares, B. B. Identificação dos fatores associados ao uso da suplementação do ácido fólico na gestação. Revista de Enfermagem do Centro Oeste Mineiro, 1552- 1561, 2015 FONSECA. Acesso em 02 de junho de 2020.

GADIA, Carlos A.; TUCHMAN, Roberto; ROTTA, Newra T. Autismo e doenças invasivas no desenvolvimento. J. Pediatr. (Rio J.), Porto Alegre, v. 80, n. 2, supl. p. 83-94, abril de $2004 . \quad$ Disponível em $<$ http://www.scielo.br/scielo.php?script=sci_arttext\&pid=S0021$75572004000300011 \&$ Ing=en\&nrm=iso $>$. Acesso em 10 de abril de 2020.

GRIESI-OLIVEIRA, Karina; SERTIE, Andréa Laurato. Transtornos do espectro autista: um guia atualizado para aconselhamento genético. Einstein (São Paulo), São Paulo, v. $15, \quad$ n. 2, p. 233-238, junho de 2017. Disponível em <http://www.scielo.br/scielo.php?script=sci_arttext\&pid=S1679$45082017000200233 \&$ Ing=en\&nrm=iso >. Acesso em 07 de abril de 2020.

HOFZMANN, Rafaela da Rosa et al. EXPERIÊNCIA DOS FAMILIARES NO CONVÍVIO DE CRIANÇAS COM TRANSTORNO DO ESPECTRO AUTISTA (TEA). Enfermagem em Foco, [S.I.], v. 10, n. 2, ago. 2019. ISSN 2357-707X. Disponível em: <http://revista.cofen.gov.br/index.php/enfermagem/article/view/1671/521>. Acesso em 25 de maio de 2020 .

INTERDISCIPLINARY SCIENTIFIC JOURNAL. São Carlos-SP: ISSN: 2358-8411

JARA-P, Camila et al. Impacto do ácido fólico na incidência de fissuras labiopalatais na população ocidental da região metropolitana, Chile. Int. J. Odontostomat. Temuco, v. $12, \quad$ n. 3 , p. 228-232, setembro 2018. Disponível em 
$<$ https://scielo.conicyt.cl/scielo.php?script=sci_arttext\&pid=S0718381X2018000300228\&lng=es\&nrm=iso >. Acesso em 29 de maio de 2020.

JIAXIU ZHOU, Aiping Liu, Fusheng He, Ya Jin, Shaoming Zhou, Ruihuan Xu, Hailiang Guo, Wenhao Zhou, Mingbang Wang \& Qiufen Wei (2018): High prevalence of serum folate receptor autoantibodies in children with autism spectrum disorders, Biomarkers,. Dispponível em: https://pesquisa.bvsalud.org/brasil/resource/pt/mdl29578363. Acesso em: 29 maio.2020.

JOURNAL OF MEDICINE. Patos-PB: 2018-, ISSN: 2448-1394.

KAMILA CASTRO, Luciana da Silveira Klein, Diego Baronio, Carmem Gottfried, Rudimar Riesgo \& Ingrid Schweigert Perry (2016): Folic acid and autism: What do we know?, Nutritional Neuroscience, .Disponível em https://pesquisa.bvsalud.org/brasil/resource/pt/mdl-25087906. Acesso em: 26 maio.2020.

LEEMING, R J; Lucock, M. (2009): Autism: Is there a folate connection? Disponível em: https://pesquisa.bvsalud.org/brasil/resource/pt/mdl-19277892. Acesso em: 25 maio.2020.

LEMOS, Emellyne Lima de Medeiros Dias; NUNES, Laísy de Lima; SALOMAO, Nádia Maria Ribeiro. Transtorno do Espectro Autista e Interações Escolares: Sala de Aula e Pátio. Rev. bras. educ. Bauru, v. 26, n. 1, p. 69-84, março de 2020. Disponível em $<$ http://www.scielo.br/scielo.php?script=sci_arttext\&pid=S1413$65382020000100069 \& \operatorname{lng}=e n \& n r m=i s o>$. Acesso em 29 de maio de 2020.

LIEW, Siaw-Cheok. Folic acid and diseases - supplement it or not?. Rev. Assoc. Med. Bras., São Paulo , v. 62, n. 1, p. 90-100, Feb. 2016. Diponível em: .<http://www.scielo.br/scielo.php?script=sci_arttext\&pid=S0104$42302016000100090 \& \operatorname{lng}=e n \& n r m=i s o>$. Acesso em: 27 maio.2020.

MAIA, Carina Scanoni et al . Transtorno do espectro autista e a suplementação por ácido fólico antes e durante a gestação. J. bras. psiquiatr., Rio de Janeiro , v. 68, n. 
4, p. 231-243, $\quad$ Dez. 2019. Disponível em :<http://www.scielo.br/scielo.php?script=sci_arttext\&pid=S0047$20852019000400231 \& \operatorname{lng}=e n \& n r m=i s o>$. Acesso em 20 maio.2020.

MAIA, Fernanda Alves et al. TRANSTORNO DO ESPECTRO DO AUTISMO E FATORES PÓS-NASCIDOS: UM ESTUDO DE CONTROLE DE CASO NO BRASIL. Rev. paul. pediatr., São Paulo, v. 37, n. 4, p. 398-405, dezembro de 2019. Disponível em $<$ http://www.scielo.br/scielo.php?script=sci_arttext\&pid=S010305822019000400398\&lng=en\&nrm=iso>. acesso em 29 de maio de 2020.

MONTEIRO, Manuela Albernaz et al. TRANSTORNO DO ESPECTRO DO AUTISMO: UMA REVISÃO SISTEMÁTICA SOBRE INTERVENÇÕES NUTRICIONAIS. ReV. paul. pediatr. , São Paulo, v. 38, e2018262, 2020. Disponível em <http://www.scielo.br/scielo.php?script=sci_arttext\&pid=S0103$05822020000100508 \& \operatorname{lng}=e n \& n r m=i s o>$. acesso em 29 de maio de 2020.

PEREIRA, C. C. V. Artigo de revisão: AUTISMO E FAMÍLIA: PARTICIPAÇÃO DOS PAIS NO TRATAMENTO E DESENVOLVIMENTO DOS FILHOS AUTISTAS, fev./2011. Disponível em: https://assets.unitpac.com.br/arquivos/revista/51/1.pdf. Acesso em: 22 mai. 2020.

PINTO, Rayssa Naftaly Muniz et al. Autismo infantil: IMPACTO NO DIAGNÓSTICO E REPERCUSSÕES NAS RELAÇÕES FAMILIARES. Rev. Gaúcha Enferm., Porto Alegre, v. 37, n. 3, e61572, 2016. Disponível em $<$ http://www.scielo.br/scielo.php?script=sci_arttext\&pid=S1983$14472016000300413 \&$ Ing=en\&nrm=iso $>$. Acesso em 25 de maio de 2020

POSAR, Annio; VISCONTI, Paola. Anormalidades sensoriais em crianças com transtorno do espectro autista. J. Pediatr. (Rio J.), Porto Alegre, v. 94, n. 4, p. 342350, agosto de 2018. Disponível em $<$ http://www.scielo.br/scielo.php?script=sci_arttext\&pid=S0021$75572018000400342 \&$ Ing=en\&nrm=iso > . acesso em 29 de maio de 2020. 
RAMÔA, Andreia et al. Suplementação excessiva com ácido fólico durante a gravidez e desenvolvimento de asma na infância: uma revisão baseada na evidência. Rev Port Med Geral Fam, Lisboa , v. 34, n. 2, p. 89-95, abr. 2018 . Disponível em $<$ http://www.scielo.mec.pt/scielo.php?script=sci_arttext\&pid=S2182$51732018000200005 \&$ Ing=pt\&nrm=iso >. Acesso em 29 de maio 2020.

REVISTA AUTISMO. O que é o autismo, São Paulo: 2019. ISSN 2596-0539. Trimestral.

REVISTA VEJA. O novo mundo do autismo, São Paulo: editora Abril, 2017. ISSN 0000-1122.

SANTOS, Quenia dos et al . Avaliação da segurança de diferentes doses de suplementos de ácido fólico em mulheres do Brasil. Rev. Saúde Pública, São Paulo, v. $47, \mathrm{n}$ 5 , p. 952-957,Out. 2013 Disponível em http://www.scielo.br/scielo.php?script=sci_arttext\&pid=S0034$89102013000500952 \&$ Ing=en\&nrm=iso $>$. Acesso em: 28 maio,2020.

SILVA, Lucas Silveira da; FURTADO, Luis Achilles Rodrigues. O sujeito autista na Rede SUS: (im) possibilidade de cuidado. Fractal, Rev. Psicol., Rio de Janeiro, v. 31, n. 2, p. 119-129, agosto de 2019. Disponível em $<$ http://www.scielo.br/scielo.php?script=sci_arttext\&pid=S198402922019000200119\&lng=en\&nrm=iso $>$. Acesso em 10 de maio de 2020.

UEHARA, Sofia Kimi; ROSA, Glorimar. Associação da deficiência de ácido fólico com alterações patológicas e estratégias para sua prevenção: uma visão crítica. Rev. Nutr.,Campinas, v. 23, n. 5, p. 881-894, Out. 2010 . Disponível em http://www.scielo.br/scielo.php?script=sci_arttext\&pid=S1415$52732010000500018 \&$ Ing=en\&nrm=iso $>$. Acesso em 25 de maio de 2020.

VILAR, Andréa Maria Alves et al .TRANSTORNOS AUTíSTICOS E ESTRATÉGIAS PROMOTORAS DE CUIDADOS: REVISÃO INTEGRATIVA. Rev. baiana enferm., Salvador , v. 33, e28118, 2019 . Disponível em 
$<$ http://www.revenf.bvs.br/scielo.php?script=sci_arttext\&pid=S2178-

$86502019000100502 \&$ Ing=pt\&nrm=iso $>$. acesso em 08 de maio de 2020

ZANOLLA, Thais Arbocese et al., ADAPTAÇÃO CULTURAL E EVIDÊNCIA DE VALIDADE DO INSTRUMENTO PARA UM EXAME MORFOLÓGICO REALIZADO EM CRIANÇAS COM TRANSTORNO DO ESPECTRO DE AUTISMO. Rev. paul. pediatr. , São Paulo, v. 38, e2018318, 2020. Disponível em $<$ http://www.scielo.br/scielo.php?script=sci_arttext\&pid=S010305822020000100100419\&lng=en\&nrm=iso >. acesso em 29 de maio de 2020.

ZANON, Regina Basso; BACKES, Bárbara; BOSA, Cleonice Alves. Diagnóstico do autismo: relação entre fatores contextuais, familiares e da criança. Psicol. teor. prat., São Paulo , v. 19, n. 1, p. 152-163, abr. 2017 . Disponível em http://pepsic.bvsalud.org/scielo.php?script=sci_arttext\&pid=S151636872017000100009\&lng=pt\&nrm=iso $>$. Acesso em: 26 maio. 2020.

Enviado: Agosto, 2020.

Aprovado: Dezembro, 2020. 